\title{
Molecular analysis of long-term biofilm formation on PVC and cast iron surfaces in drinking water distribution system
}

\author{
Ruyin Liu ${ }^{1, * *}$, Junge Zhu ${ }^{2, * *}$, Zhisheng $\mathrm{Yu}^{1, *}$, DevRaj Joshi ${ }^{3}$, Hongxun Zhang ${ }^{1}$, \\ Wenfang $\operatorname{Lin}^{1}$, Min Yang ${ }^{3}$ \\ 1. College of Environmental and Resource Sciences, University of Chinese Academy of Sciences, Beijing 100049, China. \\ E-mail:lry1981@126.com \\ 2. Institute of Microbiology, Chinese Academy of Sciences, Beijing 100101, China \\ 3. Research Center for Eco-Environmental Sciences, Chinese Academy of Sciences, Beijing 100085, China
}

\section{A R T I C L E I N F O}

\section{Article history:}

Received 25 May 2013

revised 07 August 2013

accepted 06 September 2013

\section{Keywords:}

drinking water

biofilm

surface material

pyrosequencing

microbial community

DOI: $10.1016 /$ S1001-0742(13)60481-7

\begin{abstract}
A B S T R A C T
To understand the impacts of different plumbing materials on long-term biofilm formation in water supply system, we analyzed microbial community compositions in the bulk water and biofilms on faucets with two different materials-polyvinyl chloride (PVC) and cast iron, which have been frequently used for more than 10 years. Pyrosequencing was employed to describe both bacterial and eukaryotic microbial compositions. Bacterial communities in the bulk water and biofilm samples were significantly different from each other. Specific bacterial populations colonized on the surface of different materials. Hyphomicrobia and corrosion associated bacteria, such as Acidithiobacillus spp., Aquabacterium spp., Limnobacter thiooxidans, and Thiocapsa spp., were the most dominant bacteria identified in the PVC and cast iron biofilms, respectively, suggesting that bacterial colonization on the material surfaces was selective. Mycobacteria and Legionella spp. were common potential pathogenic bacteria occurred in the biofilm samples, but their abundance was different in the two biofilm bacterial communities. In contrast, the biofilm samples showed more similar eukaryotic communities than the bulk water. Notably, potential pathogenic fungi, i.e., Aspergillus spp. and Candida parapsilosis, occurred in similar abundance in both biofilms. These results indicated that microbial community, especially bacterial composition was remarkably affected by the different pipe materials (PVC and cast iron).
\end{abstract}

\section{Introduction}

Despite oligotrophic conditions and the presence of disinfectants, both bacterial and eukaryotic groups can inhabit the bulk water or biofilm in drinking-water distribution system (DS). Biofilm is generally recognized as the primary source of microorganisms in DS, as attached cells have certain advantages over planktonic cells (Berry et al., 2006; Emtiazi et al., 2004; Tachikawa et al., 2005).

\footnotetext{
*Corresponding author. E-mail: yuzs@ucas.ac.cn;

** Authors contribute equally to this article.
}

The occurrence of biofilm may cause many public health issues, such as protecting and supporting pathogenic microorganisms (Buswell et al., 1998), bacterial regrowth (LeChevallier et al., 1991), depletion of disinfection agents (Regan et al., 2002) and microbial corrosion (Holden et al., 1995; LeChevallier et al., 1993). Thus, the DS biofilm has received more concerns.

Due to limited access and high cost involved in sampling, many studies have used model DS or removable coupons for biofilm attachment inserted (for short times) in real DSs (Berry et al., 2006). However, because the formation of biofilm is a result of successional development 
into a mature community, that may require several years before a steady state is achieved (Martiny et al., 2003), which limits the relevance of short-term model studies. In our previous research, it was found that the faucet biofilm with about 2 years development still show many characteristics of young biofilm (Liu et al., 2012a). Overall, current information on the microbial community of longterm biofilm within full-scale DSs is scant, especially for biofilm eukaryotic community.

The biofilm formation depends on many factors prevailing in DS, wherein type of surface material is an important one (Niquette et al., 2001; Piriou et al., 1997; Rogers et al., 1994). Biofilm formations on different pipe materials have been focused by many studies. Waines et al. (2011) compared the biofilm formation on four plumbing materials (copper, stainless steel, ethylene propylene diene monomer (EPDM) and cross-linked polyethylene (PEX)) after 84 days development, and found that plastic-based PEX and EPDM supported significantly higher levels of biofilm. In contrast, Kerr et al. (1998) observed that plastic-based medium density polyethylene (MDPE) and unplasticized polyvinyl chloride (uPVC) supported the lowest number of bacteria compared with cast iron, but the diversity of heterotrophic bacteria was greatest on cast iron. These contradicted results indicate that pipe material is still one of the complicated effects on biofilm formation.

We have compared the bacterial diversity of the biofilms on three different materials (polyvinyl chloride (PVC), cast iron, and stainless steel) with a long-term formation by the cloning and sequencing methods (Lin et al., 2013). Nevertheless, the actual bacterial diversity may be masked and underestimated because of the limited throughput of clone library (Claesson et al., 2010). On the other hand, eukaryotic community was not analyzed in that work. Eukaryotes have been reported to be closely associated with bacterial biofilms (Hunt and Parry, 1998). Furthermore, some eukaryotes (e.g. amoeba) may facilitate human-pathogenic bacteria in DSs, and some are pathogenic themselves (Siqueira et al., 2011; Thomas and Ashbolt, 2011; Trofa et al., 2008). Thereby, it is interesting to know the impacts of different plumbing materials on the composition of biofilm eukaryotic community. Consequently, in the present study, in order to comprehensively understand the effects of different pipe materials on microbial community composition of longterm DS biofilm, the high-throughput 454 pyrosequencing approach was employed to analyze variations among both bacterial and eukaryotic communities in the bulk water and the biofilms on faucets with different materials (PVC and cast iron) that have been frequently used for more than 10 years.

\section{Materials and methods}

\subsection{Sampling and DNA extraction}

The detailed sampling and DNA extracting procedure are described elsewhere (Lin et al., 2013). In brief, two faucets with different materials, PVC and cast iron, located in a drinking water distribution system of Hubei Province, China, have been installed in the kitchen of one household since 2001, and frequently used every day. Mature biofilms should have been established well on the inner surface of the faucets. Water samples were collected from the main pipe shared with the two faucets using sterilized brown glass bottles. The water quality parameters were measured according to the standard methods (GB: 57492006, China). About $5 \mathrm{~L}$ water sample was filtered with $0.22 \mu \mathrm{m}$ polycarbonate membranes (Millipore, MA, USA) to obtain the biomass for DNA extraction. The biofilms that formed on the PVC and cast iron faucets were scraped out from the inner surfaces at the connection point with the pipe line using a sterile scraper and suspended in $5 \mathrm{~mL}$ sterile water. The biofilm suspensions were centrifuged at $10,000 \times g$ for $10 \mathrm{~min}$, and then resuspended the pellets in $1 \mathrm{~mL}$ sterile water. Finally, all samples were stored at $-70^{\circ} \mathrm{C}$ before usage.

Genomic DNA in the water and biofilm samples were extracted using a FastDNA spin kit (MP Biomedicals, Santa Ana, USA) facilitated with the FastPrep-24 bead beater system, following the manufacturer's instructions, and then quantified with a Nanodrop 1000 spectrophotometer (Thermo Scientific, Wilmington, DE). The extracted nucleic acids were kept at $-70^{\circ} \mathrm{C}$ until use.

\subsection{Scanning electron microscopy}

The faucets were broken with a hammer. Small patches of the broken faucets were placed in a fixative that contained $2.5 \%$ glutaraldehyde $(W / V)$ and $2.0 \%$ paraformaldehyde $(W / V)$. The faucet samples were fixed overnight, and then washed three times (15 min each) with $\mathrm{ddH}_{2} \mathrm{O}$. The samples were dehydrated by incubation in increasing concentrations of ethanol and then dried at the critical point with a $\mathrm{CO}_{2}$ critical point drier (Tousimis, MD). The samples were sputter coated with gold and viewed with a Hitachi S-3000N scanning electron microscopy (Japan).

\subsection{PCR and pyrosequencing}

The 16S rRNA genes of bacteria were amplified from genomic DNA using primers 27F (5'-AGA GTT TGA TCC TGG CTC AG-3') and 533R (5'-TTA CCG CGG CTG CTG GCA C-3') (Benitez-Paez et al., 2013). The $18 \mathrm{~S}$ rRNA genes of eukaryotes were amplified using primers 3NDf (5'-GGC AAG TCT GGT GCC AG-3') and V4_euk_R2 (5'-ACG GTA TCT (AG)AT C(AG)T CTT CG-3') (Brate et al., 2010). Barcodes that allow sample multiplexing during pyrosequencing were incorporated in 
the 5' end of primer 533R and 3NDf. PCR mixtures (20 $\mu \mathrm{L})$ were prepared in duplicate and each contained $10 \mathrm{ng}$ of DNA template, $4 \mu \mathrm{L}$ of $5 \times$ FastPfu buffer, $250 \mu \mathrm{mol} / \mathrm{L}$ of dNTPs, $0.8 \mu \mathrm{L}$ of each $5 \mu \mathrm{mol} / \mathrm{L}$ primer and $0.4 \mu \mathrm{L}$ FastPfu polymerase (TransGen Biotech, China). The PCR reactions were performed with the following program: $95^{\circ} \mathrm{C}$ for $2 \mathrm{~min} ; 20$ cycles at $95^{\circ} \mathrm{C}$ for $30 \mathrm{sec}, 56^{\circ} \mathrm{C}$ for $30 \mathrm{sec}, 72^{\circ} \mathrm{C}$ for $30 \mathrm{sec}$, and then $72^{\circ} \mathrm{C}$ for $5 \mathrm{~min}$. Purified PCR products of target genes of bacteria and eukaryotes were sequenced by pyrosequencing method on a 454 Life Sciences Genome Sequencer FLX (Roche Diagnostics, Indianapolis, USA) machine. Sequences and quality scores were submitted to the NCBI short read archive (accession number SRA061928).

\subsection{Phylogenetic analysis}

All sequence reads obtained from pyrosequencing were quality checked using Mothur software (Schloss et al., 2009). Any poor quality reads were removed. Raw sequence reads were filtered before subsequent analyses to minimize the effects of random sequencing errors. Briefly, we eliminated sequence reads that did not perfectly match the proximal PCR primer, were too short $(<200 \mathrm{bp})$, contained one or more ambiguous base(s)-, or checked as chimeric artifact. The rest of sequences were trimmed and classified using Bayesian approach with the Silva database (Pruesse et al., 2007) as template, and a cutoff of $80 \%$. Mothur software was also used to construct the distance matrices, assign sequences to operational taxonomic units (OTUs, 97\% similarity) and calculate Good's coverage, abundance based coverage estimator (ACE), Chaol richness estimator and Shannon diversity indices.

\section{Results and discussion}

\subsection{Morphology of the biofilms}

The morphology of biofilms developed on the inner surface of the cast iron and PVC faucets were studied by scanning electron microscope (SEM). SEM analysis revealed obviously different biofilm patterns on the two faucets with different materials. Porous and unleveled coral-like deposits occurred in the cast iron faucet (Fig. 1a), which should be the corroded particles agglomerated and loosely covered with bacteria cells. The observation was comparable with that of corroded cast iron coupons under chlorine residue in water (Liu et al., 2002; Wang et al., 2011). The inner surface of PVC faucet was covered with a layer of extracellular matrix material (Fig. 1b), where microbes were clumped and embedded. Matrix material was also observed previously on the surface of plastic substratum in water meters and showerheads (Feazel et al., 2009; Hong et al., 2010). Majorly, populations of rod-shaped bacteria were observed in the PVC biofilm.

\subsection{Microbial diversity and richness}

Partial SSU RNA gene sequences of bacteria and eukaryota were amplified using universal primer pairs $27 \mathrm{~F} / 533 \mathrm{R}$, and 3NDf/V4_euk_R2, respectively. After eliminating sequence reads that did not perfectly match the proximal PCR primer, were too short $(<200 \mathrm{bp})$, contained one or more ambiguous base(s)-, or checked as chimeric artifact, 10085-13699 (average length of $461 \mathrm{bp}$ ) validated bacterial and 4298-4634 (average length of 453 bp) eukaryotic reads were retrieved from the bulk water, PVC and cast iron biofilm samples (Table 1), respectively, and were performed for further phylogenetic analysis.

Among the three biofilms, the community of the bulk water showed the median bacterial diversity with Shannon indices of 3.34, while the cast iron and PVC biofilm possessed the highest and lowest one, respectively. The eukaryotic diversity of each sample was comparable, as shown in Table 1. The coverage of the sequence libraries based on pyrosequencing, ranging from $88.6 \%$ to $96.7 \%$.

\subsection{Bacterial communities}

Proteobacteria was the most dominant group in the water and DS biofilm samples, comprising $86.99 \%-95.84 \%$ of pyrosequencing reads, of which $\alpha$-Proteobacteria was in most abundance (45.72\%-89.09\% of sequence reads). However, bacteria compositions of these samples were
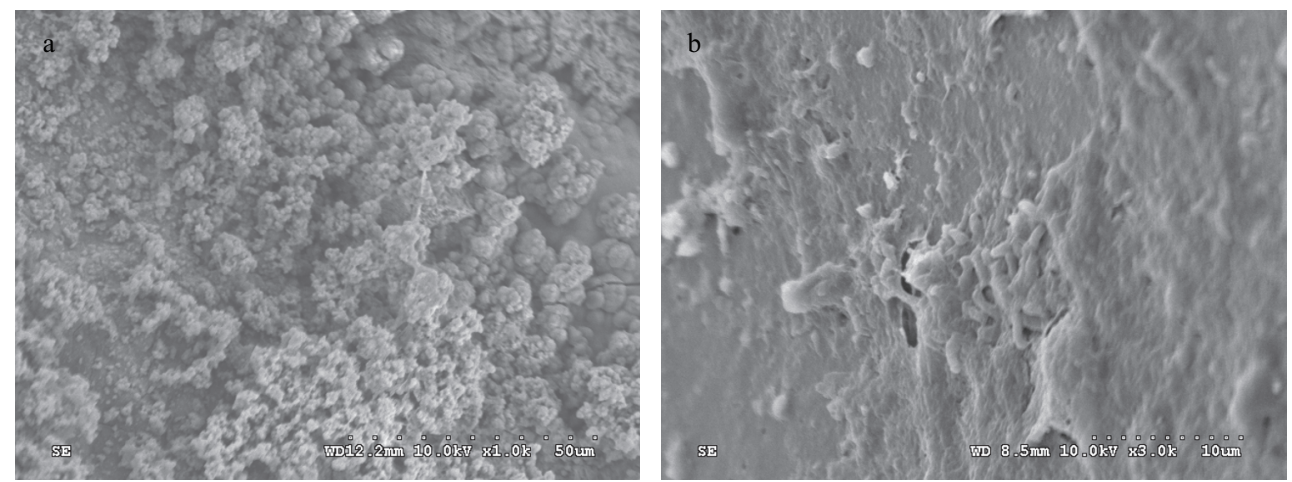

Fig. 1 Scanning electron microscopy (SEM) micrographs of the biofilm formed on the cast iron (a) and PVC (b) faucets. 
Table 1 Diversity indices and coverage of bacterial and eukaryotic communities

\begin{tabular}{llllllll} 
Sample (domain) & OTUs $^{\mathrm{a}}$ & No. of reads $^{\mathrm{b}}$ & chao $^{\mathrm{c}}$ & ACE $^{\mathrm{d}}$ & Shannon & Simpson & Coverage (\%) $^{\text {( }}$ \\
\hline Cast iron (Bacteria) & 874 & 10614 & 1820 & 2351 & 4.60 & 0.03 & 95.6 \\
PVC (Bacteria) & 729 & 13699 & 1731 & 2833 & 2.28 & 0.41 & 96.7 \\
Water (Bacteria) & 802 & 10085 & 2027 & 3463 & 3.44 & 0.11 & 94.8 \\
Cast iron (Eukaryotes) & 712 & 4298 & 2087 & 3516 & 4.26 & 0.06 & 88.7 \\
PVC (Eukaryotes) & 570 & 4634 & 1511 & 2676 & 4.22 & 0.04 & 92.1 \\
Water (Eukaryotes) & 744 & 4302 & 2000 & 3410 & 4.38 & 0.06 & 88.6 \\
\hline
\end{tabular}

${ }^{a}$ The operational taxonomic units (OTU) were determined with a $3 \%$ width; ${ }^{b}$ Trim reads that passed quality controls; ${ }^{\mathrm{c}}$ chao1 richness estimates;

d ACE richness estimates.

significantly different from each other $(p=0.0001$, LIBSHUFF analysis), as shown in Fig. 2. Only 28 OTUs were shared by all of them (Fig. 3), mainly falling into the orders Rhizobiales, Sphingomonadales, Burkholderiales, and Pseudomonadales, most members of which were common residents in fresh water habitats or biofilms in water distribution systems (Liu et al., 2012b; Simoes et al., 2008). $\beta$-Proteobacteria $(24.14 \%)$ was the second largest bacterial group in the cast iron biofilm community, followed by $\gamma$-Proteobacteria $(16.81 \%)$, Bacteroidetes $(6.02 \%)$, Planctomycetes $(2.16 \%)$, and Actinobacteria $(2.02 \%)$, whereas Actinobacteria (5.82\%) was the second most dominant group in the PVC biofilm, followed by $\gamma$-Proteobacteria $(2.45 \%)$ (Fig. 4). In contrast,

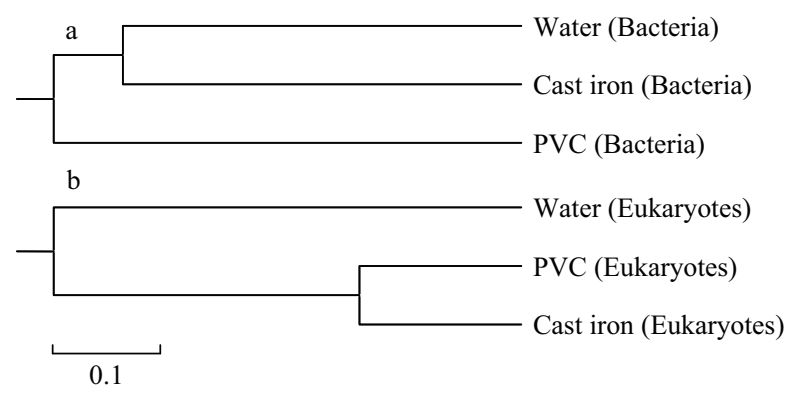

Fig. 2 Bacterial (a) and eukaryotic (b) community clustering based on the $16 / 18 \mathrm{~S}$ rRNA gene pyrosequencing reads using the thetayc calculator of Mothur software with a $3 \%$ distance threshold.

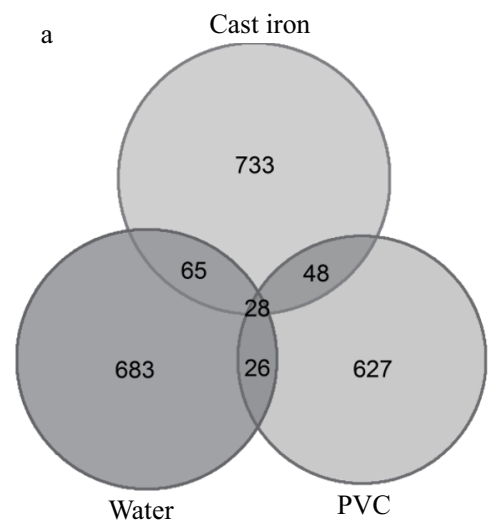

other major bacterial groups in the bulk water included $\gamma$-Proteobacteria $(13.11 \%), \beta$-Proteobacteria $(6.03 \%)$, and Actinobacteria (2.49\%).

The bacterial groups identified by pyrosequencing analysis covered all of those detected by the low-throughput clone library, while the abundances of dominant groups were different with each other as revealed by the two molecular approaches (Lin et al., 2013). Meanwhile, pyrosequencing analysis identified some specific bacterial groups, such as the Planctomycetes and Actinobacteria. These observations were likely due to: (1) preferential PCR amplification leaded by the different primer sets (27F/533R primers targeting variable V1, V2, and V3 regions of the $16 \mathrm{~S}$ rRNA gene used for the pyrosequencing; 27F/1492R primers targeting almost full length of the $16 \mathrm{~S}$ rRNA gene used for the clone library), (2) different cycles of PCR amplification (20 cycles of amplification for the pyrosequencing with the aim to minimize PCR bias amplification; 35 cycles for the clone library) (Sipos et al., 2007), and (3) much higher resolution of high-throughput pyrosequencing than clone library sequencing technology (Claesson et al., 2010).

One notable characteristic of the PVC biofilm was the predominance of Hyphomicrobium-like phylotypes representing $66.6 \%$ of PVC pyrosequences, whereas $\mathrm{Hy}$ phomicrobium relatives comprised $7.14 \%$ and $2.63 \%$ of pyrosequences in the cast iron biofilm and drinking-water

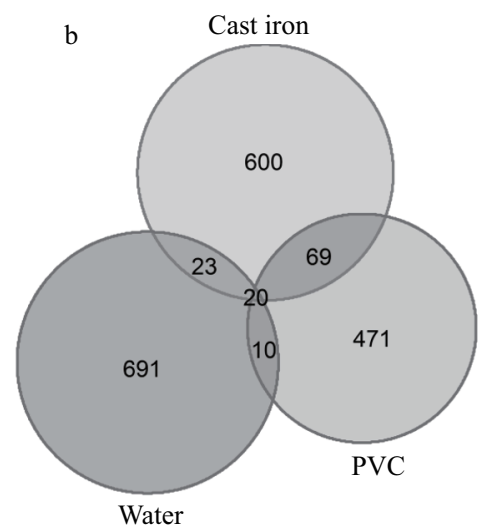

Fig. 3 Venn diagrams of bacterial (a) and eukaryotic (b) OTUs clustered with a 3\% distance threshold, showing the number of OTUs shared by the biofilm and water samples. 


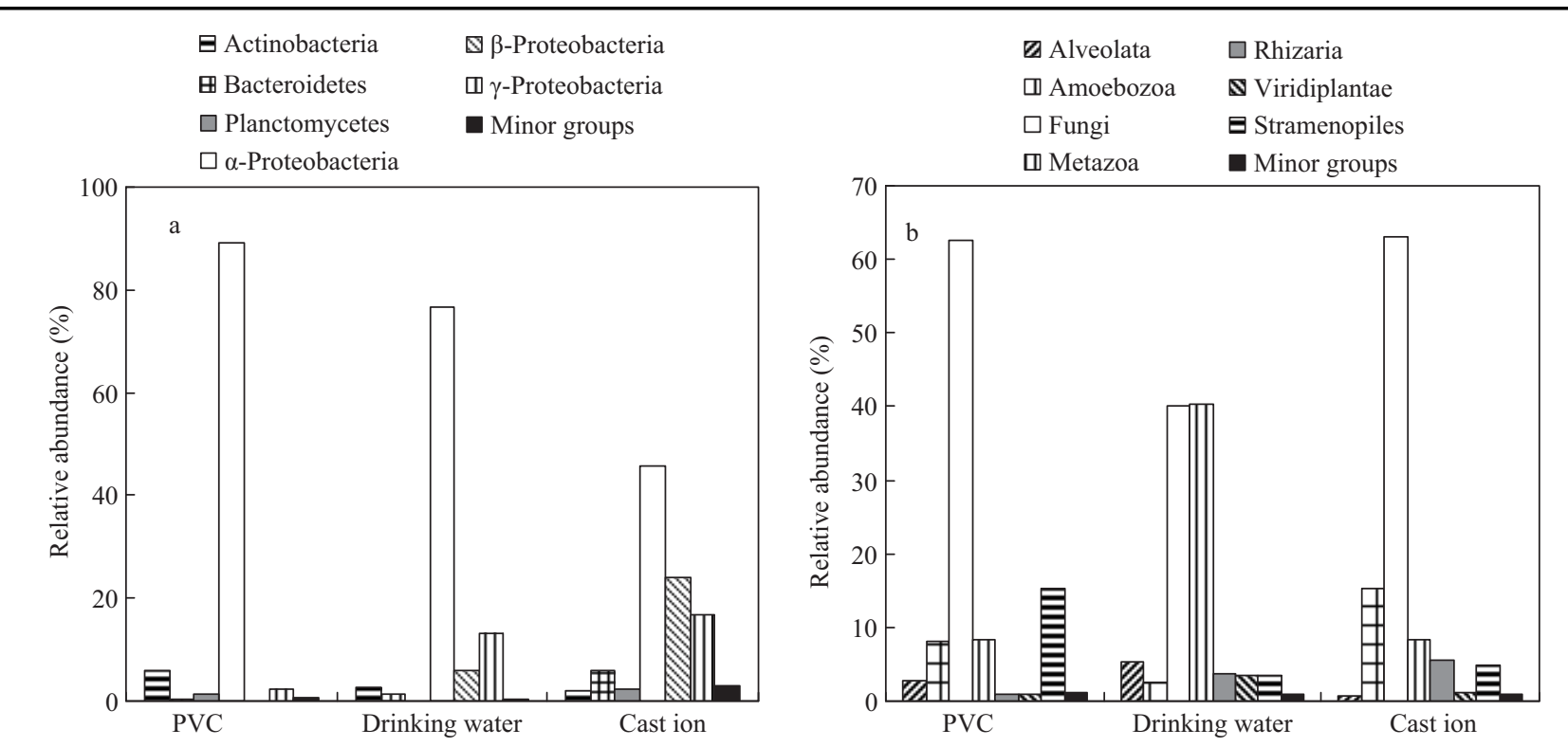

Fig. 4 Richness and abundance distribution of bacterial (a) and eukaryotic (b) populations in the biofilm samples. The taxonomic group whose abundance is $<1 \%$ in all three biofilm communities was not shown, wrapped in the Minor groups.

samples, respectively (Table 2). Most of hyphomicrobia are appendaged bacteria that multiply by budding, with the ability of nitrogen-fixing and denitrifying (Fesefeldt et al., 1998). In terms of carbon utilization, members of Hyphomicrobium are restricted facultative methylotrophs, growing on $\mathrm{C} 1$ components, such as methanol, methylated amines, and formate etc, but not compounds with three or more carbon atoms. High frequency of hyphomicrobia implied that C1-compounds possibly produced by other organisms through cross feeding should be the central carbon or energy resources in the PVC biofilm. In a study of biofilms developed on water meter, Hong et al. (2010) found that methylotrophs of the genus Methylophilus comprised the major bacterial communities, and indicated that these methylotrophs might utilize the methanol supplied by some methanothophs. Except the hyphomicrobia, other methylotrophs of the genus Methylobacterium were also found in the DS biofilms (Table 2). The capability of utilizing nitrogen and C1-compounds might confer hyphomicrobia ecological advantages for their growth in nutritionally poor DS ecosystems.

Bacterial composition of the cast iron biofilm was clearly different from those of the PVC biofilm, and the difference was primarily attributed to the occurrence of a number of corrosion-associated bacteria. In the cast iron biofilm, $0.27 \%$ of pyrosequences showed close homology to iron-oxidizing acidophile Acidithiobacillus spp. despite a neutral pH (7.2) of the bulk water (Lin et al., 2013). Members of Acidithiobacillus can grow at $\mathrm{pH}$ values of 4.5 to 1.3 and derive its biosynthetic requirements by autotrophy using carbon from atmospheric carbon dioxide. Occurrence of the acidophilic Fe-oxidizer might be associated with the abundant sulfur-oxidizers, mainly including Limnobacter thiooxidans (3.1\%) and Thiocapsalike phylotypes $(3.1 \%)$. The sulfur-oxidizers could convert ferrous sulfide to sulfuric acid, producing acidic niches and releasing ferrous iron in the process, which in turn could be utilized by the acidophilic Fe-oxidizers. In addition, Aquabacterium-like bacteria (7.4\%) were found abundantly in the cast iron biofilm, while few relevant species occurred in the PVC biofilm and water samples $(0.02 \%$ and $0.01 \%$, respectively). Some Aquabacterium species, having ability of oxidizing ferrous iron with nitrate as electron acceptor under anoxic conditions, were reported (Straub et al., 2004). In this study, the most of cast iron pyrosequences classified into the genus Aquabacterium were closely related to the clone HN14 from an ironreducing bacterium enrichment culture (Wang et al., 2009), suggesting that the Aquabacterium relatives in the cast iron biofilm may be associated with iron corrosion.

Metal corrosion has been examined in distribution systems, including both electrochemical corrosion and microbiologically influenced corrosion (Lin et al., 2001; Starosvetsky et al., 2001). Because very little energy can be generated during the oxidation of ferrous to ferric iron, a large quantity of iron needs to be oxidized to support the growth of iron oxidizing bacteria. It has been calculated that the ratio of iron to the weight of a bacterial cell could be up to approximately 450 to 500 , assuming that the oxidation of ferrous iron provides the sole energy for the synthesis of cell material (Cullimore and McCann, 1977). Thus, it is suggested that the metal corrosion accelerates on the surface of cast iron by abundant corrosion-associated bacteria. Pipe corrosion is known to affect microbial adhesion and biofilm formation (Waines et al., 2011). The ferrous iron released during the corrosion process 
Table 2 Identified bacterial genera in the drinking-water and biofilm communities

\begin{tabular}{|c|c|c|c|c|c|c|c|}
\hline Genus & $\begin{array}{l}\text { Polyvinyl } \\
\text { chloride (\%) }\end{array}$ & $\begin{array}{l}\text { Water } \\
(\%)\end{array}$ & $\begin{array}{l}\text { Cast } \\
\text { iron (\%) }\end{array}$ & Genus & $\begin{array}{l}\text { Polyvinyl } \\
\text { chloride (\%) }\end{array}$ & $\begin{array}{l}\text { Water } \\
(\%)\end{array}$ & $\begin{array}{l}\text { Cast } \\
\text { iron (\%) }\end{array}$ \\
\hline Aquabacterium & 0.02 & 0.01 & 7.41 & Methylocystis & 0.01 & 0.27 & 0.04 \\
\hline Achromobacter & 0.01 & 0 & 0.2 & Methyloversatilis & 0.01 & 0 & 0.83 \\
\hline Acidithiobacillus & 0 & 0 & 0.27 & Microbacterium & 0.15 & 0.88 & 0.46 \\
\hline Acidovorax & 0.01 & 0.43 & 0.44 & Micrococcus & 0 & 0.16 & 0 \\
\hline Acinetobacter & 1.78 & 11.51 & 0.22 & Mucilaginibacter & 0 & 0 & 0.38 \\
\hline Ancalomicrobium & 0.69 & 0 & 0 & Muricoccus & 0 & 21.76 & 0 \\
\hline Arthrobacter & 0.01 & 0.29 & 0.03 & Mycobacterium & 5.61 & 0.05 & 0.56 \\
\hline Arthrobacter & 0.01 & 0.29 & 0.03 & Nevskia & 0 & 0 & 3.07 \\
\hline Azospira & 0.01 & 0 & 0.1 & Nitrospira & 0 & 0.01 & 0.29 \\
\hline Bacillus & 0.24 & 0.01 & 0.03 & Nocardioides & 0 & 0.01 & 0.12 \\
\hline Blastomonas & 0.25 & 0.83 & 0.11 & Novosphingobium & 0.07 & 1.55 & 0.57 \\
\hline Bosea & 0.08 & 0.35 & 0.08 & Parvularcula & 0.01 & 0 & 0.12 \\
\hline Brachybacterium & 0 & 0.39 & 0 & Pedobacter & 0 & 0 & 0.38 \\
\hline Bradyrhizobium & 0.26 & 0.03 & 1.17 & Pelomonas & 0 & 0.11 & 1.14 \\
\hline Brevibacterium & 0 & 0.12 & 0.01 & Perlucidibaca & 0.01 & 0.04 & 2.51 \\
\hline Brevundimonas & 0.07 & 0.11 & 0.41 & Phenylobacterium & 0 & 0.04 & 0.38 \\
\hline Castellaniella & 0.03 & 0.19 & 1.34 & Planctomyces & 0 & 0.01 & 0.17 \\
\hline Caulobacter & 0.01 & 0.22 & 0.02 & Pleomorphomonas & 5.33 & 0.01 & 0 \\
\hline Chryseobacterium & 0.05 & 0.18 & 0.44 & Porphyrobacter & 2.92 & 0.04 & 4.04 \\
\hline Cloacibacterium & 0 & 0 & 0.23 & Propionivibrio & 0 & 0 & 1.64 \\
\hline Comamonas & 0.01 & 0.19 & 0.22 & Prosthecomicrobium & 0.14 & 0 & 0 \\
\hline Deinococcus & 0.02 & 0.01 & 0.52 & Pseudomonas & 0.16 & 1.02 & 2.8 \\
\hline Delftia & 0 & 0.1 & 0.05 & Pseudorhodoferax & 0 & 0.08 & 0.67 \\
\hline Diaphorobacter & 0 & 0 & 0.23 & Rheinheimera & 0.09 & 0.15 & 0.26 \\
\hline Duganella & 0 & 0.26 & 0 & Rhizobium & 0.58 & 0.05 & 0.24 \\
\hline Dyadobacter & 0 & 0 & 0.2 & Rhodobacter & 3.42 & 0.12 & 0.92 \\
\hline Enterobacter & 0.08 & 0.08 & 0.03 & Rhodoblastus & 0.04 & 0.16 & 0.01 \\
\hline Erythromicrobium & 0 & 0.03 & 2.04 & Rhodovarius & 0 & 0.28 & 0 \\
\hline Filomicrobium & 0.92 & 0 & 0 & Roseomonas & 0.02 & 3.09 & 0.08 \\
\hline Flavobacterium & 0.16 & 0.69 & 0.11 & Ruegeria & 1.18 & 0 & 0 \\
\hline Flectobacillus & 0.06 & 0 & 0.67 & Runella & 0 & 0 & 0.15 \\
\hline Flexibacter & 0.02 & 0 & 0.17 & Sediminibacterium & 0 & 0.03 & 0.56 \\
\hline Fluviicola & 0 & 0 & 0.9 & Singularimonas & 0 & 0 & 0.43 \\
\hline Gemmata & 0.28 & 0 & 1.36 & Solimonas & 0 & 0 & 0.25 \\
\hline Gordonia & 0.01 & 0.01 & 0.29 & Sphingobacterium & 0.09 & 0.29 & 0.12 \\
\hline Hydrocarboniphaga & 0 & 0 & 0.87 & Sphingobium & 0.11 & 0.41 & 0.29 \\
\hline Hydrogenophaga & 0 & 0.03 & 1.48 & Sphingomonas & 1.9 & 1.52 & 6.87 \\
\hline Hyphomicrobium & 66.6 & 2.63 & 7.14 & Sphingopyxis & 0.68 & 0.03 & 0.02 \\
\hline Klebsiella & 0.14 & 0 & 0 & Spirosoma & 0 & 0 & 0.34 \\
\hline Legionella & 0.03 & 0 & 1.06 & Telmatospirillum & 0.42 & 0 & 0.17 \\
\hline Limnobacter & 0 & 0 & 3.1 & Thiocapsa & 0 & 0 & 3.1 \\
\hline Lutibacter & 0 & 0 & 0.45 & Thiorhodospira & 0 & 0 & 0.73 \\
\hline Massilia & 0 & 0.14 & 0.12 & Undibacterium & 0 & 0.22 & 0.11 \\
\hline Methylobacterium & 0.99 & 0 & 0.25 & Vogesella & 0 & 0.16 & 0.01 \\
\hline
\end{tabular}

may scavenge residual chlorine, reducing the efficacy of disinfection so as to create favorable conditions for the growth of bacteria in DSs ( $\mathrm{Li}$ et al., 2010). Furthermore, the iron-oxidizer can precipitate iron oxides by converting ferrous iron to ferric iron (Volk et al., 2000), while that could make the surface of cast iron pipe rougher. The rough surface may concentrate organic nutrients. Hence, the biofilm regrowth on rough surface materials such as cast iron and galvanized steel was greater than that on smooth surface of PVC pipe (Chowdhury, 2012; Yu et al., 2010), and more rapid biofilm development was also observed on iron pipes than on other piping materials (Camper, 1996). Based on these results, it can be concluded that the corrosion on the cast iron may promote the biofilm formation and possibly support more diverse niches, and hence responsible for the higher bacterial diversity of the 
cast iron biofilm than that on the surface of PVC (Table 1).

In terms of potential waterborne pathogenic bacteria, $0.14 \%$ of pyrosequences from the PVC biofilm were closely related to Klebsiella pneumoniae that may infect those with impaired immune systems, sometimes causing destructive pneumonia. Mycobacterium spp. were found in both the water and biofilm samples, whereas Legionella spp. occurred only in the biofilm samples (Table 2). This finding was in agreement with previous studies that members of these genera were common potential pathogens in the oligotrophic water supply systems (Giao et al., 2009; Liu et al., 2012a; Vaerewijck et al., 2005), but their abundances were clearly different in the PVC and cast iron biofilms. Mycobacterium spp. were more dominant $(5.61 \%)$ in the PVC biofilm than that in the water $(0.05 \%)$ and cast iron biofilm $(0.56 \%)$ samples. In contrast, more abundant Legionella spp. (1.06\%) occurred in the cast iron biofilm as compared with the PVC biofilm $(0.03 \%)$. Due to the complex cell wall, mycobacteria are generally resistant to several disinfectants, e.g. chlorine, chloramines. The resistance confers their selective advantage for natural competence in chlorine-containing DSs. Besides, mycobacteria have hydrophobic cell surface, and hydrophobic interactions between the cells and the hydrophobic surface would mediate attachment and biofilm formation (Vaerewijck et al., 2005). Thus, it is reasonable that the PVC surface favors mycobacteria adherence due to its hydrophobic character during the early stages of biofilm formation. On the other hand, Mycobacterium spp. and Legionella spp. seem to proliferate in different strategies, i.e. $K$ - and $r$-strategists, respectively. Mycobacteria grow slowly but possess strong disinfection tolerance, whereas Legionella spp. are more susceptible to residual chlorine in potable water. Although intracellular growth within amoeba was frequently reported essential for their resistance to chlorination stress and persistence in DSs, some studies showed that residual chlorine could exert negative impacts on the growth of Legionella spp., and in some cases Legionella bacteria outnumbered mycobacteria in DS biofilms under low disinfection levels but different in turn under heavy disinfection stress (Pryor et al., 2004; van der Kooij et al., 2005). Considering the consumption of chlorine during the corrosion process, low-chlorine or even chlorine-free niches might extensively exist in the cast iron biofilm, resulting in the higher occurrence of Legionella species.

Within the bulk water, Muricoccus and Acinetobacter were the dominant genera, comprising $21.76 \%$ and $11.51 \%$ of pyrosequences, respectively, while their abundances declined markedly in the biofilm samples (Table 2). Members of these genera were possibly well adapted to the planktonic growth. Commonly, the microorganisms in DS biofilms are derived from the bulk water, but the significant difference was found among the microbial communities of the water and biofilm samples. As compared with the bulk water community, certain bacterial populations selectively enriched in the biofilms developed on the different materials. For example, Hyphomicrobium and mycobacteria occurred in the PVC biofilm, whereas ironcorrosion associated bacteria and Legionella spp. were found in the cast iron biofilm. These results indicated that different pipe materials (PVC and cast iron) significantly affected bacterial community compositions of DS biofilms, and bacteria colonization was selective on the surfaces of PVC and cast iron materials.

\subsection{Eukaryotic communities}

In view of the close association of eukaryotes with biofilm microbiota and some pathogens, the eukaryotic communities were revealed by the pyrosequencing approach in this study. Although the bacterial communities were significantly different among the water and biofilm samples, eukaryote community compositions were similar in these samples (Figs. 2 and 3). As shown in Fig. 4, fungi was the most primary group, comprising $62.47 \%$ and $63.12 \%$ of eukaryotic pyrosequences in the PVC and cast iron biofilms respectively, followed by Amoebozoa, Metazoa, and Stramenopiles. The majority of pyrosequences from the bulk water were classified into Metazoa (40.26\%) and Fungi $(40.09 \%)$.

Only few of previous studies have focused fungi in distribution systems (Doggett, 2000; Nagy and Olson, 1982). Most of the fungi identified in this study belonged to the phylum Ascomycota $(37.79 \%-62.52 \%)$. And those in the PVC and cast iron biofilms were further classified into the subphyla Pezizomycotina $(36.69 \%$ and $44.46 \%$, respectively) and Saccharomycotina $(19.18 \%$ and 9.84 $\%$, respectively), while those in the bulk water mainly belonged to Pezizomycotina (34.44\%). Many filamentous Pezizomycotina fungi were found in these samples, such as Cladosporium spp. (8.80\%-14.93\%) and Aspergillus spp. (5.79\%-9.42\%). Their occurrences in drinking water or biofilms have been reported (Doggett, 2000; Sammon et al., 2010). Recently, using atomic force microscope, Abe et al. (2011) found that biofilm aggregates were embedded in an extensive network of filamentous fungi during the development of drinking-water biofilm, and indicated that the fungal structure may assist in reinforcing biofilm adhesion to a substratum surface. Saccharomycotina fungi were prevalent in the biofilm samples, implying their adaption to the attached growth. Of them, the heavy occurrence of Pichia spp. (7.47\%) was observed in the PVC biofilm, while Candida yeasts, especially Candida parapsilosis relatives were abundant $(8.20 \%$ and $7.89 \%$, respectively) in the biofilm samples despite of different substratum materials. It is noteworthy that $C$. parapsilosis is now one of the leading causes of invasive candidal disease, and biofilm formation is recognized as one of the important factor involved in disease pathogenesis (Trofa et al., 2008). Besides, high occurrences of Aspergillus spp. 
in the water and biofilms also should be concerned as some species were found associated with clinical samples causing human diseases, and potent toxins (mycotoxin) production (Roselle and Baird, 1979; Siqueira et al., 2011).

The preying eukaryotes were mainly distributed into the phyla Metazoa and Amoebozoa. Among the members of phylum Metazoa, many Halicephalobus-like nematodes were detected in both the water (15\%) and biofilm samples (7.24\%-7.62\%), while Lecithodendriidae-like flatworms were abundant in the drinking-water eukaryotic community $(23.72 \%)$. Amoeba was more abundant in the biofilm samples, but different amoeba populations were detected on different substratum surfaces. Platyamoeba (13.82\%) and Hartmannella vermiformis $(4.36 \%)$ were the dominant amoeba in the cast iron and PVC biofilms, respectively. Previous study had also reported the prevalence of $H$. vermiformis in the DS biofilms formed on the plastic substratum (Liu et al., 2012a).

In this point of view, PVC seems more suitable as plumbing material in drinking water distribution systems, given that the cast iron faucet supports more complex bacterial diversity than the PVC faucet. Besides, some previous studies showed that plastic-based materials support less biofilm biomass than metal materials (Kerr et al., 1998; Niquette et al., 2000). However, the abundance of potential pathogens in the DS biofilms, especially Mycobacterium and Legionella species in the PVC and cast iron biofilm respectively, and heavy occurrence of eukaryotic Aspergillus spp. and C. parapsilosis in both of them, implied that the biological safety of pipe materials is considerable and should be given more attention in future studies.

\section{Conclusions}

Based on the pyrosequencing analysis, this work indicated that the pipe materials (PVC and cast iron) may remarkably influence microbial community, especially the bacterial compositions in the long-term developed DS biofilms. Diverse but different genera of microorganisms, derived from bulk water may colonize on the surfaces of PVC and cast iron materials selectively. Nevertheless, it is hard to determine which pipe material (PVC and cast iron) is suitable to use as a major plumbing component in water delivery system because the potential bacterial and eukaryotic pathogens occurred in biofilms developed over both materials.

\section{Acknowledgments}

This work was supported by the National Natural Science Foundation of China (No. 51208501), the Key Research Program of the Chinese Academy of Sciences (No. KZZDEW-09-1), and the Program of the Chinese Academy of Sciences (No. Y025014EA2).
R E F E R E N C E S

Abe, Y., Polyakov, P., Skali-Lami, S., Francius, G., 2011. Elasticity and physico-chemical properties during drinking water biofilm formation. Biofouling 27(7), 739-750.

Benitez-Paez, A., Alvarez, M., Belda-Ferre, P., Rubido, S., Mira, A., Tomas, I., 2013. Detection of transient bacteraemia following dental extractions by $16 \mathrm{~S}$ rDNA pyrosequencing: A pilot study. Plos One 8(3), e57782.

Berry, D., Xi, C.W., Raskin, L., 2006. Microbial ecology of drinking water distribution systems. Current Opinion in Biotechnol. 17(3), 297-302.

Brate, J., Logares, R., Berney, C., Ree, D.K., Klaveness, D., Jakobsen, K.S. et al., 2010. Freshwater Perkinsea and marine-freshwater colonizations revealed by pyrosequencing and phylogeny of environmental rDNA. ISME J. 4(9), 1144-1153.

Buswell, C.M., Herlihy, Y.M., Lawrence, L.M., McGuiggan, J.T., Marsh, P.D. et al., 1998. Extended survival and persistence of Campylobacter spp. in water and aquatic biofilms and their detection by immunofluorescent-antibody and -rRNA staining. Appl. Environ. Microbiol. 64(2), 733-741.

Camper, A.K., 1996. Factors limiting microbial growth in the distribution system laboratory, pilot-scale experiments. Denver, Colo: American Water Works Association Research Foundation, American Water Works Association.

Chowdhury, S., 2012. Heterotrophic bacteria in drinking water distribution system: a review. Environ. Monit. Assess., 184(10), 6087-6137.

Claesson, M.J., Wang, Q.O., O’Sullivan, O., Greene-Diniz, R., Cole, J.R., Ross, R. P. et al., 2010. Comparison of two next-generation sequencing technologies for resolving highly complex microbiota composition using tandem variable $16 \mathrm{~S}$ rRNA gene regions. Nucleic Acids Res. 38(22): e200.

Cullimore, D., McCann, A.E., 1977. The identification, cultivation and control of iron bacteria in ground water. In: Skinner, F.A., Shewan, J.M., (Eds.). Aquatic Microbiology Academic Press, London. 219261.

Doggett, M. S., 2000. Characterization of fungal biofilms within a municipal water distribution system. Appl. Environ. Microbiol. 66(3), 1249-1251.

Emtiazi, F., Schwartz, T., Marten, S.M., Krolla-Sidenstein, P., Obst, U., 2004. Investigation of natural biofilms formed during the production of drinking water from surface water embankment filtration. Water Res. 38(5), 1197-1206.

Feazel, L.M., Baumgartner, L.K., Peterson, K.L., Frank, D.N., Harris, J.K., Pace, N. R., 2009. Opportunistic pathogens enriched in showerhead biofilms. Proc. Natl Acad. Sci. USA. 106(38), 1639316398.

Fesefeldt, A., Kloos, K., Bothe, H., Lemmer, H., Gliesche, C., 1998. Distribution of denitrification and nitrogen fixation genes in $\mathrm{Hy}$ phomicrobium spp. and other budding bacteria. Can. J. Microbiol. 44(2), 181-186.

Giao, M.S., Wilks, S., Azevedo, N.F., Vieira, M.J., Keevil, C.W., 2009. Incorporation of natural uncultivable Legionella pneumophila into potable water biofilms provides a protective niche against chlorination stress. Biofouling 25(4), 345-351.

Holden, B., Greetham, M., Croll, B., Scutt, J., 1995. The effect of changing inter process and final disinfection reagents on corrosion and biofilm growth in distribution pipes. Water Sci. Technol. 32(8), 
213-220

Hong, P.Y., Hwang, C.C., Ling, F.Q., Ersen, G.L., LeChevallier, M.W., Liu, W.T., 2010. Pyrosequencing analysis of bacterial biofilm communities in water meters of a drinking water distribution system. Appl. Environ. Microbiol. 76(16), 5631-5635.

Hunt, A.P., Parry, J.D., 1998. The effect of substratum roughness and river flow rate on the development of a freshwater biofilm community. Biofouling 12(4), 287-303.

Kerr, C.J., Osborn, K.S., Roboson, G.D., Handley, P.S., 1998. The relationship between pipe material and biofilm formation in a laboratory model system. J. Appl. Microbiol. 85(S1), 29-38.

LeChevallier, M.W., Lowry, C.D., Lee, R.G., Gibbon, D.L., 1993. Examining the relationship between iron corrosion and the disinfection of biofilm bacteria. J. Amer. Water Works Assoc. 85(7), 111-123.

LeChevallier, M.W., Schulz, W., Lee, R.G., 1991. Bacterial nutrients in drinking water. Appl. Environ. Microbiol. 57(3), 857-862.

Li, D., Li, Z., Yu, J.W., Cao, N., Liu, R.Y., Yang, M., 2010. Characterization of bacterial community structure in a drinking water distribution system during an occurrence of Red Water. Appl. Environ. Microbiol. 76(21), 7171-7180.

Lin, J.P., Ellaway, M., Adrien, R., 2001. Study of corrosion material accumulated on the inner wall of steel water pipe. Corrosion Sci. 43(11), 2065-2081.

Lin, W., Yu, Z., Chen, X., Liu, R., Zhang, H., 2013. Molecular characterization of natural biofilms from household taps with different materials: PVC, stainless steel, and cast iron in drinking water distribution system. Appl. Microbiol. Biotechnol. 97(18), 83938401.

Liu, R., Yu, Z., Guo, H., Liu, M., Zhang, H., Yang, M., 2012a. Pyrosequencing analysis of eukaryotic and bacterial communities in faucet biofilms. Sci. Total Environ. 435-436, 124-131.

Liu, R., Yu, Z., Zhang, H., Yang, M., Shi, B., Liu, X., 2012b. Diversity of bacteria and mycobacteria in biofilms of two urban drinking water distribution systems. Can. J. Microbiol. 58(3), 261-270.

Liu, W., Wu, H., Wang, Z., Ong, S., Hu, J., Ng, W., 2002. Investigation of assimilable organic carbon (AOC) and bacterial regrowth in drinking water distribution system. Water Res. 36(4), 891-898.

Martiny, A.C., Jorgensen, T.M., Albrechtsen, H.J., Arvin, E., Molin, S., 2003. Long-term succession of structure and diversity of a biofilm formed in a model drinking water distribution system. Appl. Environ. Microbiol. 69(11), 6899-6907.

Nagy, L.A., Olson, B.H., 1982. The occurrence of filamentous fungi in drinking-water distribution-systems. Can. J. Microbiol 28(6), 667671.

Niquette, P., Servais, P., Savoir, R., 2000. Impacts of pipe materials on densities of fixed bacterial biomass in a drinking water distribution system. Water Res. 34(6), 1952-1956.

Niquette, P., Servais, P., Savoir, R., 2001. Bacterial dynamics in the drinking water distribution system of Brussels. Water Res. 35(3), 675-682.

Piriou, P., Dukan, S., Levi, Y., Jamge, P., 1997. Prevention of bacterial growth in drinking water distribution systems. Water Sci. Technol. 35(11-12), 283-287.

Pruesse, E., Quast, C., Knittel, K., Fuchs, B. M., Ludwig, W.G., Peplies, J. et al., 2007. SILVA: a comprehensive online resource for quality checked and aligned ribosomal RNA sequence data compatible with ARB. Nucleic Acids Res. 35(21), 7188-7196.

Pryor, M., Springthorpe, S., Riffard, S., Brooks, T., Huo, Y., Davis, G. et al., 2004. Investigation of opportunistic pathogens in municipal drinking water under different supply and treatment regimes. Water Sci. Technol. 50(1), 83-90.

Regan, J.M., Harrington, G.W., Noguera, D.R., 2002. Ammonia- and nitrite-oxidizing bacterial communities in a pilot-scale chloraminated drinking water distribution system. Appl. Environ. Microbiol. 68(1), 73-81.

Rogers, J., Dowsett, A.B., Dennis, P. J., Lee, J.V., Keevil, C.W., 1994. Influence of plumbing materials on biofilm formation and growth of Legionella pneumophila in potable water systems. Appl. Environ. Microbiol. 60(6), 1842-1851.

Roselle, G. A., Baird, I.M., 1979. Aspergillus flavipes group osteomyelitis. Arch. Int. Medic. 139(5), 590-592.

Sammon, N.B., Harrower, K.M., Fabbro, L.D., Reed, R.H., 2010. Incidence and distribution of microfungi in a treated municipal water supply system in sub-tropical Australia. Int. J. Environ. Res. Public Health 7(4), 1597-1611.

Schloss, P.D., Westcott, S.L., Ryabin, T., Hall, J.R., Hartmann, M., Hollister, E. B. et al., 2009. Introducing mothur: open-Source, platform-Independent, community-supported software for describing and comparing microbial communities. Appl. Environ. Microbiol. 75(23), 7537-7541.

Simoes, L.C., Simoes, M., Vieira, M.J., 2008. Intergeneric coaggregation among drinking water bacteria: Evidence of a role for Acinetobacter calcoaceticus as a bridging bacterium. Appl. Environ. Microbiol. 74(4), 1259-1263.

Sipos, R., Szekely, A. J., Palatinszky, M., Revesz, S., Marialigeti, K., Nikolausz, M., 2007. Effect of primer mismatch, annealing temperature and PCR cycle number on 16S rRNA gene-targetting bacterial community analysis. FEMS Microbiol. Ecol. 60(2), 341350 .

Siqueira, V.M., Oliveira, H.M.B., Santos, C., Paterson, R.R.M., Gusmao, N.B., Lima, N., 2011. Filamentous fungi in drinking water, particularly in relation to biofilm formation. Inter. J. Environ. Res. Public Health 8(2), 456-469.

Starosvetsky, D., Armon, R., Yahalom, J., Starosvetsky, J., 2001. Pitting corrosion of carbon steel caused by iron bacteria. Int. Biodeterior. Biodegrad. 47(2), 79-87.

Straub, K.L., Schonhuber, W.A., Buchholz-Cleven, B.E.E., Schink, B., 2004. Diversity of ferrous iron-oxidizing, nitrate-reducing bacteria and their involvement in oxygen-independent iron cycling. Geomicrobiol. J. 21(6), 371-378.

Tachikawa, M., Tezuka, M., Morita, M., Isogai, K., Okada, S., 2005. Evaluation of some halogen biocides using a microbial biofilm system. Water Res. 39(17), 4126-4132.

Thomas, J.M., Ashbolt, N.J., 2011. Do free-Living amoebae in treated drinking water systems present an emerging health risk? Environ. Sci. Technol. 45(3), 860-869.

Trofa, D., Gacser, A., Nosanchuk, J.D., 2008. Candida parapsilosis, an emerging fungal pathogen. Clini. Microbiol. Rev. 21(4), 606625.

Vaerewijck, M. J.M., Huys, G., Palomino, J.C., Swings, J., Portaels, F., 2005. Mycobacteria in drinking water distribution systems: ecology and significance for human health. Fems Microbiol. Rev. 29(5), 911-934.

van der Kooij, D., Veenendaal, H.R., Scheffer, W.J.H., 2005. Biofilm formation and multiplication of Legionella in a model warm water system with pipes of copper, stainless steel and cross-linked 
polyethylene. Water Res. 39(13), 2789-2798.

Volk, C., Dundore, E., Schiermann, J., Lechevallier, M., 2000. Practical evaluation of iron corrosion control in a drinking water distribution system. Water Res. 34(6), 1967-1974.

Waines, P. L., Moate, R., Moody, A.J., Allen, M., Bradley, G., 2011. The effect of material choice on biofilm formation in a model warm water distribution system. Biofouling 27(10), 1161-1174.

Wang, H., Hu, C., Hu, X., Yang, M., Qu, J., 2011. Effects of disinfectant and biofilm on the corrosion of cast iron pipes in a reclaimed water distribution system. Water Res. 46(4), 1070-1078.

Wang, X.J., Yang, J., Chen, X.P., Sun, G.X., Zhu, Y.G., 2009. Phylogenetic diversity of dissimilatory ferric iron reducers in paddy soil of Hunan, South China. J. Soil. Sedim. 9(6), 568-577.

Yu, J., Kim, D., Lee, T., 2010. Microbial diversity in biofilms on water distribution pipes of different materials. Water Sci. Technol. 61(1), 163-171. 